\title{
PCA-based bootstrap confidence interval tests for gene-disease association involving multiple SNPs
}

\author{
Qianqian Peng ${ }^{1}$, Jinghua Zhao ${ }^{2^{*}}$, Fuzhong Xue ${ }^{1^{*}}$
}

\begin{abstract}
Background: Genetic association study is currently the primary vehicle for identification and characterization of disease-predisposing variant(s) which usually involves multiple single-nucleotide polymorphisms (SNPs) available. However, SNP-wise association tests raise concerns over multiple testing. Haplotype-based methods have the advantage of being able to account for correlations between neighbouring SNPS, yet assuming Hardy-Weinberg equilibrium (HWE) and potentially large number degrees of freedom can harm its statistical power and robustness. Approaches based on principal component analysis $(P C A)$ are preferable in this regard but their performance varies with methods of extracting principal components $(P C S)$.

Results: $P C A$-based bootstrap confidence interval test (PCA-BCIT), which directly uses the $P C$ scores to assess genedisease association, was developed and evaluated for three ways of extracting $P(s$, i.e., cases only(CAES), controls only(COES) and cases and controls combined(CES). Extraction of PCS with COES is preferred to that with CAES and CES. Performance of the test was examined via simulations as well as analyses on data of rheumatoid arthritis and heroin addiction, which maintains nominal level under null hypothesis and showed comparable performance with permutation test.
\end{abstract}

Conclusions: PCA-BCIT is a valid and powerful method for assessing gene-disease association involving multiple SNPS.

\section{Background}

Genetic association studies now customarily involve multiple SNPs in candidate genes or genomic regions and have a significant role in identifying and characterizing disease-predisposing variant(s). A critical challenge in their statistical analysis is how to make optimal use of all available information. Population-based case-control studies have been very popular[1] and typically involve contingency table tests of SNP-disease association[2]. Notably, the genotype-wise Armitage trend test does not require $H W E$ and has equivalent power to its allele-wise counterpart under $H W E[3,4]$. A thorny issue with individual tests of SNPs for linkage disequilibrium $(L D)$ in such setting is multiple testing, however, methods for multiple testing adjustment assuming independence such as Bonferroni's[5,6] is knowingly

\footnotetext{
* Correspondence: jinghua.zhao@mrc-epid.cam.ac.uk; xuefzh@sdu.edu.cn
'Department of Epidemiology and Health Statistics, School of Public Health,

* Correspondence: jinghua.zhao@mrc-epid.cam.ac.uk; xuefzh@sdu.edu.cn
'Department of Epidemiology and Health Statistics, School of Public Health, Shandong University, Jinan 250012, PR China

${ }^{2}$ MRC Epidemiology Unit, Institute of Metabolic Science, Addenbrooke's Hospital, Cambridge CB2 OQQ, UK
}

(c) 2010 Peng et al; licensee BioMed Central Ltd. This is an Open Access article distributed under the terms of the Creative Commons Attribution License (http://creativecommons.org/licenses/by/2.0), which permits unrestricted use, distribution, and reproduction in any medium, provided the original work is properly cited. taneously. The genotype-wise Armitage trend test is appealing since it is equivalent to the score test from logistic regression[8] of case-control status on dosage of disease-predisposing alleles of SNP. However, testing for the effects of multiple SNPs simultaneously via logistic regression is no cure for difficulty with multicollinearity and curse of dimensionality[9]. Haplotype-based methods have many desirable properties[10] and could possibly alleviate the problem[11-14], but assumption of $H W E$ is usually required and a potentially large number of degrees of freedom are involved[7,11,15-18].

It has recently been proposed that $P C A$ can be combined with logistic regression test $(L R T)[7,16,17]$ in a unified framework so that $P C A$ is conducted first to account for between-SNP correlations in a candidate region, then $L R T$ is applied as a formal test for the association between $P C$ scores (linear combinations of the original SNPs) and disease. Since PCs are orthogonal, it avoids multicollinearity and at the meantime is conservative[7]. It is therefore necessary to seek alterna- 
less computer-intensive than haplotype-based methods. Studies have shown that $P C A-L R T$ is at least as powerful as genotype- and haplotype-based methods[7,16,17]. Nevertheless, the power of $P C A$-based approaches vary with ways by which $P C$ s are extracted, e.g., from genotype correlation, LD, or other kinds of metrics[17], and in principle can be employed in frameworks other than logistic regression[7,16,17]. Here we investigate ways of extracting $P C s$ using genotype correlation matrix from different types of samples in a case-control study, while presenting a new approach testing for gene-disease association by direct use of $P C$ scores in a $P C A$ based bootstrap confidence interval test ( $P C A-B C I T)$. We evaluated its performance via simulations and compared it with $P C A-L R T$ and permutation test using real data.

\section{Methods}

\section{PCA}

Assume that $p$ SNPs in a candidate region of interest have coded values $\left(X_{1}, X_{2}, \ldots, X_{p}\right)$ according to a given genetic model (e.g., additive model) whose correlation matrix is C. PCA solves the following equation,

$$
C l_{i}-\lambda l_{i}=0
$$

where $l_{i}^{\prime} l_{i}=1, i=1,2, \ldots, p, l_{i}=\left(l_{i 1}, l_{i 2}, \ldots, l_{i p}\right)^{\prime}$ are loadings of PCs. The score for an individual subject is

$$
F_{i}=l_{i 1} X_{1}+l_{i 2} X_{2}+\cdots+l_{i p} X_{p}, i=1,2, \cdots, p,
$$

where $\operatorname{cov}\left(F_{i}, F_{j}\right)=0, i \neq j$, and $\operatorname{var}\left(F_{1}\right) \geq \operatorname{var}\left(F_{2}\right) \geq \ldots$ $\geq \operatorname{var}\left(F_{p}\right)$.

\section{Methods of extracting $P C s$}

Potentially, $P C A$ can be conducted via four distinct extracting strategies $(E S)$ using case-control data, i.e., 0. Calculate $P C$ scores of individuals in cases and controls separately $(S E S), 1$. Use cases only $(C A E S)$ to obtain loadings for calculation of $P C$ scores for subjects in both cases and controls, 2. Use controls only (COES) to obtain the loadings for both groups, and 3 . Use combined cases and controls (CES) to obtain the loadings for both groups. It is likely that in a case-control association study, loadings calculated from cases and controls can have different connotations and hence we only consider scenarios 1-3 hereafter. More formally, let $\left(X_{1}\right.$, $\left.X_{2}, \ldots, X_{p}\right)$ and $\left(Y_{1}, Y_{2}, \ldots, Y_{p}\right)$ be $p$-dimension vectors of SNPs at a given candidate region for cases and controls respectively, then we have,

Strategy 1 (CAES):

$$
C_{X X} l_{i}^{1}-\lambda l_{i}^{1}=0
$$

where $C_{X X}$ is the correlation matrix of $\left(X_{1}, X_{2}, \ldots, X_{p}\right)$, $l_{i}^{1}=\left(l_{i 1}^{1}, l_{i 2}^{1}, \cdots, l_{i p}^{1}\right)^{\prime}$ and $l_{i}^{1^{\prime}} l_{i}^{1}=1, i=1,2, \ldots, p$. The $i^{t h}$ $P C$ for cases is calculated by

$$
F_{i}^{D}=l_{i 1}^{1} X_{1}+l_{i 2}^{1} X_{2}+\cdots+l_{i p}^{1} X_{p}
$$

and for controls

$$
F_{i}^{C}=l_{i 1}^{1} Y_{1}+l_{i 2}^{1} Y_{2}+\cdots+l_{i p}^{1} Y_{p}
$$

Strategy 2 (COES):

$$
C_{Y Y} l_{i}-\lambda l_{i}=0
$$

where $C_{Y Y}$ is the correlation matrix of $\left(Y_{1}, Y_{2}, \ldots, Y_{p}\right)$. The $i^{\text {th }} P C$ for controls is calculated by

$$
F_{i}^{C}=l_{i 1} Y_{1}+l_{i 2} Y_{2}+\cdots+l_{i p} Y_{p}
$$

And for cases, the $i^{\text {th }} P C, \mathrm{i}=1,2, \ldots, p$, is calculated by

$$
F_{i}^{D}=l_{i 1} X_{1}+l_{i 2} X_{2}+\cdots+l_{i p} X_{p}
$$

Strategy $3(\boldsymbol{C E S})$ :

$$
C \tilde{l}_{i}-\lambda \tilde{l}_{i}=0
$$

where $C$ is the correlation matrix obtained from the pooled data of cases and controls, $\tilde{l}_{i}=\left(\tilde{l}_{i 1}, \tilde{l}_{i 2}, \cdots, \tilde{l}_{i p}\right)^{\prime}$ and $\tilde{l}_{i}{ }^{\prime} \tilde{l}_{i}=1, i=1,2, \cdots, p$. The $i^{\text {th }} P C$ of cases is calculated by

$$
F_{i}^{D}=\tilde{l}_{i 1} X_{1}+\tilde{l}_{i 2} X_{2}+\cdots+\tilde{l}_{i p} X_{p}
$$

The $i^{t h} P C$ of controls is calculated by

$$
F_{i}^{C}=\tilde{l}_{i 1} Y_{1}+\tilde{l}_{i 2} Y_{2}+\cdots+\tilde{l}_{i p} Y_{p}
$$

\section{PCA-BCIT}

Given a sample of $N$ cases and $M$ controls with $p$-SNP genotypes $\left(X_{1}, X_{2}, \ldots, X_{N}\right)^{T},\left(Y_{1}, Y_{2}, \ldots, Y_{M}\right)^{T}$, and $X_{i}=$ $\left(X_{1 i}, X_{2 i}, \ldots, x_{p i}\right)$ for the $i^{t h}$ case, $Y_{i}=\left(Y_{1 i}, Y_{2 i}, \ldots, y_{p i}\right)$ for the $i^{\text {th }}$ control, a PCA-BCIT is furnished in three steps:

\section{Step 1: Sampling}

Replicate samples of cases and controls are obtained with replacement separately from $\left(X_{1}{ }^{(b}, X_{2}{ }^{(b)}, \ldots, X_{N}{ }^{(b)}\right)^{T}$ and $\left(Y_{1}^{(b}, Y_{2}{ }^{(b)}, \ldots, Y_{M}{ }^{(b)}\right)^{T}, b=1,2, \ldots, B(B=1000)$.

Step 2: $P C A$

For each replicate sample obtained at Step 1, PCA is conducted and a given number of $P C$ s retained with a 
threshold of $80 \%$ explained variance for all three strategies[16], expressed as $\left(F_{1}^{D}, F_{2}^{D}, \cdots, F_{K}^{D}\right)^{(b)}$ and $\left(F_{1}^{C}, F_{2}^{C}, \cdots, F_{K}^{C}\right)^{(b)}$.

\section{Step 3: PCA-BCIT}

3a) For each replicate, the mean of the $k^{t h} P C$ in cases is calculated by

$$
\operatorname{mean}\left(F_{k}^{D}\right)^{(b)}=\frac{1}{N} \sum_{i=1}^{N} F_{k i}^{D(b)}
$$

and that of the $k^{t h} P C$ in controls is calculated by

$$
\operatorname{mean}\left(F_{k}^{C}\right)^{(b)}=\frac{1}{M} \sum_{j=1}^{M} F_{k j}^{C(b)}
$$

3b) Given confidence level (1 - $\alpha)$, the confidence interval of mean $\left(F_{k}^{D}\right)^{(b)}$ is estimated by percentile method, with form

$$
\begin{aligned}
& \left(P_{k \frac{\alpha}{2}}^{D}{ }_{k\left(1-\frac{\alpha}{2}\right)}^{D}\right) \text { for case } \\
& \text { where } P_{k \frac{\alpha}{2}}^{D} \text { is the } 100 \frac{\alpha}{2} \text { th percentile of } \\
& \operatorname{mean}\left(F_{k}^{D}\right)^{(b)}, \text { and } P_{k\left(1-\frac{\alpha}{2}\right)}^{D} \text { is the } 100\left(1-\frac{\alpha}{2}\right) \text { th }
\end{aligned}
$$

percentile.

The confidence interval of mean $\left(F_{k}^{C}\right)^{(b)}$ is estimated by

$$
\left(P_{k \frac{\alpha}{2}}^{C}{ }_{k\left(1-\frac{\alpha}{2}\right)}^{C}\right) \text { for control }
$$

where $P_{k \frac{\alpha}{2}}^{C}$ is the $100 \frac{\alpha}{2}$ th percentile of mean $\left(F_{k}^{C}\right)^{(b)}$, and $P_{k\left(1-\frac{\alpha}{2}\right)}^{C}$ is the $100\left(1-\frac{\alpha}{2}\right)$ th percentile.

3c) Confidence intervals of cases and controls are compared. The null hypothesis is rejected if $\left(P_{k \frac{\alpha}{2}}^{D}, P_{k\left(1-\frac{\alpha}{2}\right)}^{D}\right)$ and $\left(P_{k \frac{\alpha}{2}}^{C}, P_{k\left(1-\frac{\alpha}{2}\right)}^{C}\right)$ do not overlap, which is mean $\left(F_{k}^{D}\right)^{(b)}$ and mean $\left(F_{k}^{C}\right)^{(b)}$ are statistically different[19], indicating the candidate region is significantly associated with disease at level $\alpha$. Otherwise, the candidate region is not significantly associated with disease at level $\alpha$.

\section{Simulation studies}

We examine the performance of $P C A-B C I T$ through simulations with data from the North American Rheumatoid Arthritis (RA) Consortium (NARAC) (868 cases and 1194 controls)[20], taking advantage of the fact that association between protein tyrosine phosphatase nonreceptor type 22 (PTPN22) and the development of RA has been established[21-24]. Nine SNPs have been selected from the PNPT22 region (114157960114215857), and most of the SNPs are within the same LD block (Figure 1). Females are more predisposed $(73.85 \%)$ and are used in our simulation to ensure homogeneity. The corresponding steps for the simulation are as follows.

\section{Step 1: Sampling}

The observed genotype frequencies in the study sample are taken to be their true frequencies in populations of infinite sizes. Replicate samples of cases and controls of given size $(N, N=100,200, \ldots, 1000)$ are generated whose estimated genotype frequencies are expected to be close to the true population frequencies while both the allele frequencies and $L D$ structure are maintained. Under null hypothesis, replicate cases and controls are sampled with replacement from the controls. Under alternative hypothesis, replicate cases and controls are sampled with replacement from the cases and controls respectively.

\section{Step 2: PCA-BCITing}

For each replicate sample, $P C A-B C I T s$ are conducted through the three strategies of extracting $P C s$ as outlined above on association between $P C$ scores and disease (RA).

\section{Step 3: Evaluating performance of PCA-BCITs}

Repeat steps 1 and 2 for $K(K=1000)$ times under both null and alternative hypotheses, and obtain the frequencies $\left(P_{\alpha}\right)$ of rejecting null hypothesis at level $\alpha(\alpha=$ 0.05).

\section{Applications}

PCA-BCITs are applied to both the NARAC data on PTPN22 in 1493 females (641 cases and 852 controls) described above and a data containing nine SNPs near $\mu$-opioid receptor gene (OPRM1) in Han Chinese from Shanghai (91 cases and 245 controls) with endophenotype of heroin-induced positive responses on first use [25]. There are two LD blocks in the region of gene OPRM1 (Figure 2).

\section{Results}

\section{Simulation study}

The performance of $P C A-B C I T$ is shown in Table 1 for the three strategies given a range of sample sizes. It can be seen that strategies 2 and 3 both have type I error rates approaching the nominal level $(\alpha=0.05)$, but those from strategy 1 deviate heavily. When sample size larger than 800 , the power of PCA-BCIT is above 0.8 , and strategies 2 and 3 outperform strategy 1 slightly.

\section{Applications}

For the NARAC data, Armitage trend test reveals none of the SNPs in significant association with RA using Bonferroni correction (Table 2), but the results of $P C A$ $B C I T$ with strategies 2 and 3 show that the first $P C$ 


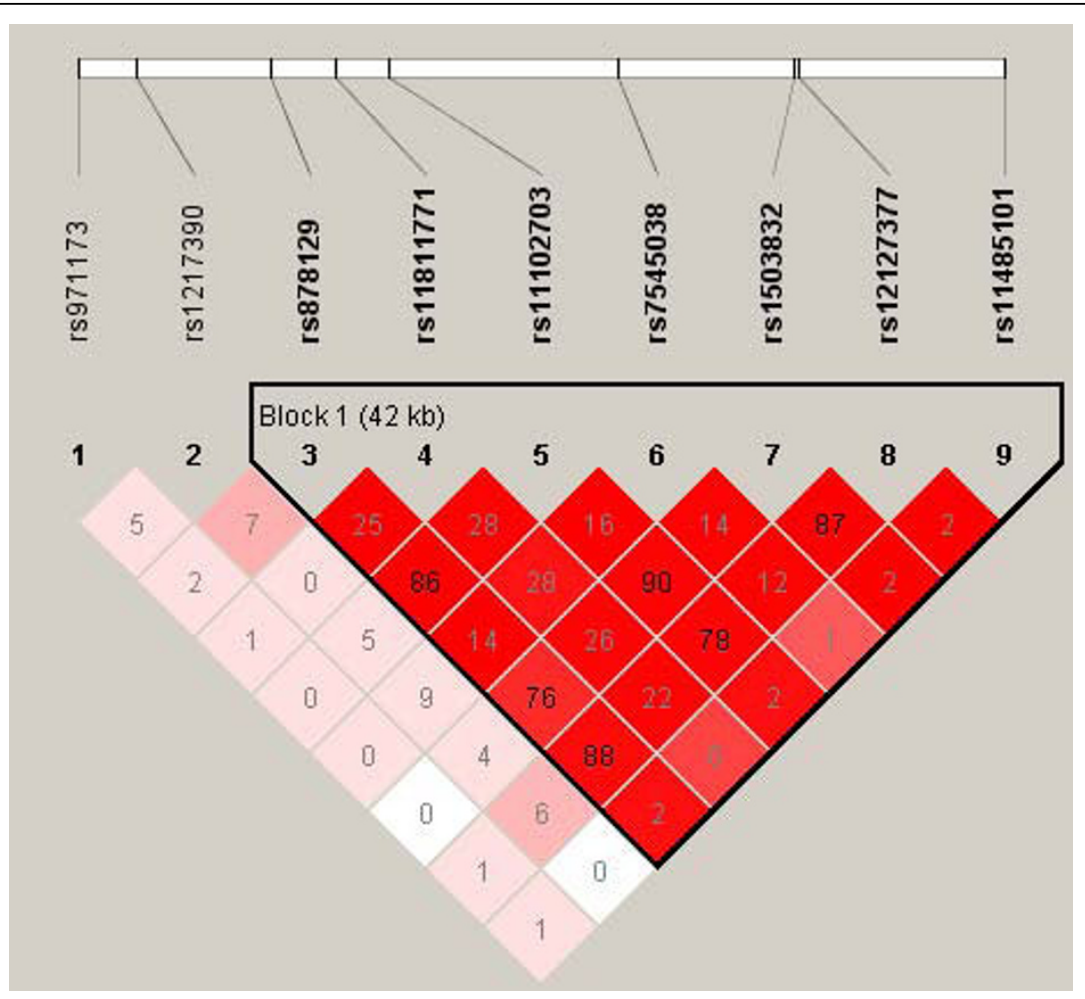

Figure 1 LD $\left(r^{2}\right)$ among nine PTPN22 SNPs. The nine PTPN22 SNPs are rs971173, rs1217390, rs878129, rs11811771, rs 11102703, rs7545038, rs1503832, rs12127377, rs11485101. The triangle marks a single LD block within this region: (rs878129, rs11811771, rs11102703, rs7545038, rs1503832, rs12127377, rs11485101).

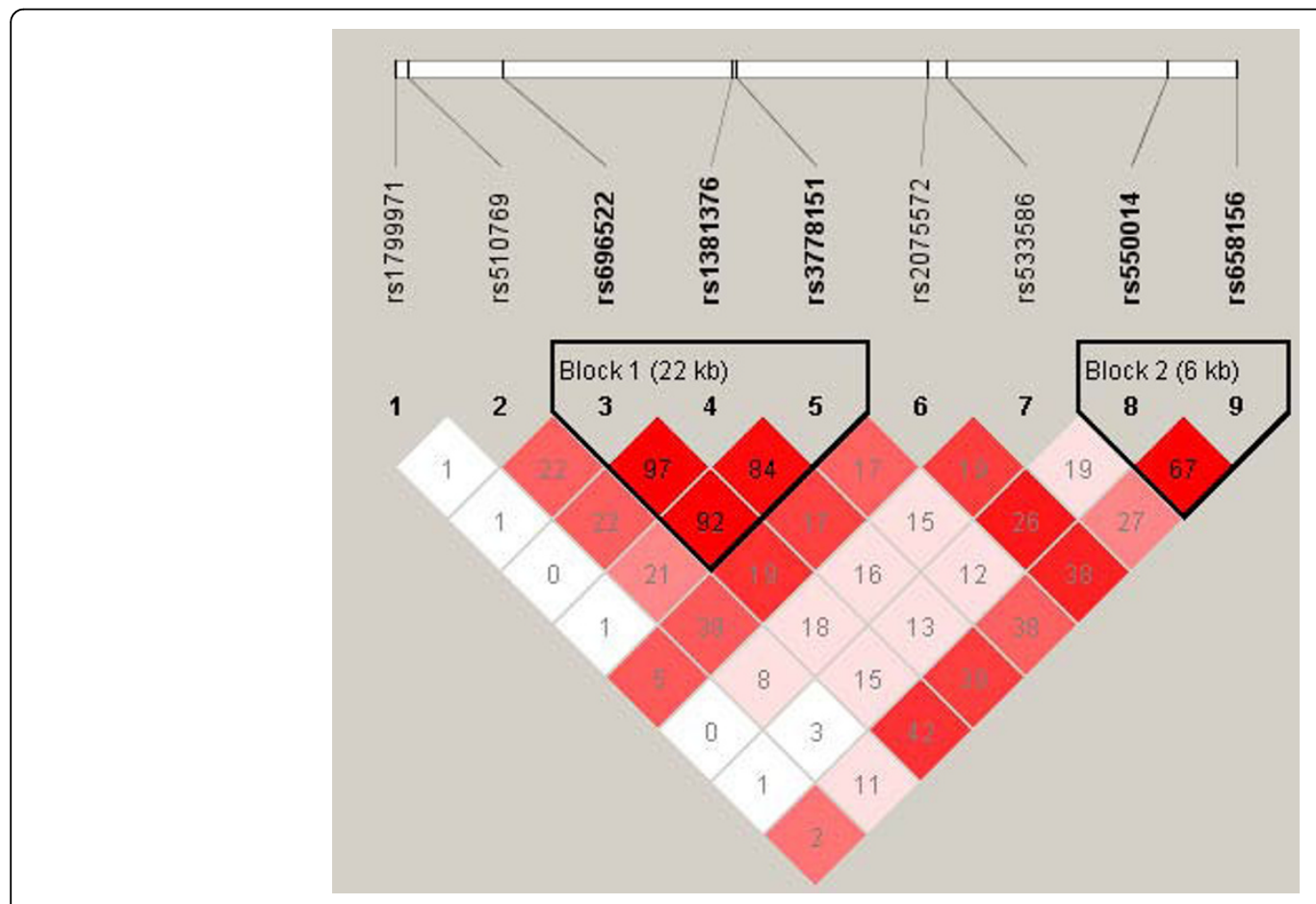

Figure 2 LD $\left(r^{2}\right)$ among nine OPRM1 SNPs. The nine OPRM1 SNPs are rs1799971, rs510769, rs696522, rs1381376, rs3778151, rs2075572, rs533586, rs550014, rs658156. The triangles mark the LD block 1 (rs696522, rs1381376, rs3778151) and LD block 2 (rs550014, rs658156). 
Table 1 Performance of PCA-BCIT at level 0.05 with strategies 1-3t

\begin{tabular}{ccccccc}
\hline Sample size & \multicolumn{3}{c}{ Type I error } & \multicolumn{3}{c}{ Power } \\
\hline & 1 & 2 & 3 & 1 & 2 & 3 \\
100 & 0.014 & 0.036 & 0.037 & 0.156 & 0.163 & 0.176 \\
200 & 0.016 & 0.044 & 0.036 & 0.249 & 0.278 & 0.292 \\
300 & 0.017 & 0.028 & 0.029 & 0.383 & 0.426 & 0.368 \\
400 & 0.014 & 0.04 & 0.02 & 0.508 & 0.485 & 0.516 \\
500 & 0.009 & 0.035 & 0.042 & 0.613 & 0.595 & 0.597 \\
600 & 0.006 & 0.032 & 0.042 & 0.677 & 0.662 & 0.683 \\
700 & 0.007 & 0.061 & 0.04 & 0.733 & 0.758 & 0.73 \\
800 & 0.004 & 0.043 & 0.045 & 0.801 & 0.791 & 0.819 \\
900 & 0.005 & 0.057 & 0.051 & 0.826 & 0.855 & 0.858 \\
1000 & 0.01 & 0.056 & 0.05 & 0.871 & 0.901 & 0.889 \\
\hline
\end{tabular}

†1 case-only extracting strategy (CAES), 2 control-only extracting strategy (COES), 3 case-control extracting strategy (CES) extracted in region of PTPN22 is significantly associated with RA. The results are similar to that from permutation test (Table 3).

For the OPRM1 data, the sample characteristics are comparable between cases and controls (Table 4), and three SNPs (rs696522, rs1381376 and rs3778151) are showed significant association with the endophenotype (Table 5). The results of PCA-BCIT with strategies 2 and 3 and permutation test are all significant at level $\alpha$ $=0.01$. In contrast, result from $P C A-L R T$ is not significant at level $\alpha=0.05$ with strategy 2 (Table 3 ). The apparent separation of cases and controls are shown in Figure 3 for $P C A-B C I T$ with strategy 3 , suggesting an intuitive interpretation.

\section{Discussion}

In this study, a $P C A$-based bootstrap confidence interval test $[19,26-28](P C A-B C I T)$ is developed to study genedisease association using all SNPs genotyped in a given region. There are several attractive features of $P C A$ -

Table 2 Armitage trend test on nine PTPN22 SNPs and RA susceptibility

\begin{tabular}{|c|c|c|c|c|c|c|c|}
\hline \multirow[t]{2}{*}{ SNP } & \multirow[t]{2}{*}{ Genotype } & \multicolumn{3}{|c|}{ Female } & \multicolumn{3}{|c|}{ Male } \\
\hline & & Case & Control & $P$-value & Case & control & $P$-value \\
\hline \multirow[t]{3}{*}{ rs971173 } & $\mathrm{CC}$ & 334 & 381 & 0.025 & 116 & 169 & 0.779 \\
\hline & $A C$ & 236 & 363 & & 85 & 134 & \\
\hline & AA & 71 & 106 & & 26 & 39 & \\
\hline \multirow[t]{3}{*}{ rs1217390 } & $\mathrm{AA}$ & 268 & 319 & 0.333 & 99 & 112 & 0.108 \\
\hline & $A G$ & 272 & 392 & & 89 & 175 & \\
\hline & GG & 98 & 138 & & 38 & 55 & \\
\hline \multirow[t]{3}{*}{ rs878129 } & GG & 338 & 507 & 0.009 & 131 & 187 & 0.384 \\
\hline & $A G$ & 251 & 291 & & 83 & 130 & \\
\hline & AA & 52 & 54 & & 13 & 25 & \\
\hline \multirow[t]{3}{*}{ rs11811771 } & AA & 224 & 272 & 0.090 & 78 & 111 & 0.717 \\
\hline & $A G$ & 303 & 411 & & 104 & 168 & \\
\hline & GG & 112 & 169 & & 45 & 62 & \\
\hline \multirow[t]{3}{*}{ rs11102703 } & $\mathrm{CC}$ & 312 & 469 & 0.024 & 121 & 174 & 0.418 \\
\hline & $A C$ & 269 & 314 & & 90 & 137 & \\
\hline & AA & 60 & 69 & & 16 & 31 & \\
\hline \multirow[t]{3}{*}{ rs7545038 } & GG & 321 & 428 & 0.696 & 109 & 186 & 0.417 \\
\hline & $A G$ & 265 & 342 & & 98 & 114 & \\
\hline & $\mathrm{AA}$ & 52 & 80 & & 20 & 40 & \\
\hline \multirow[t]{3}{*}{ rs1503832 } & AA & 324 & 487 & 0.013 & 129 & 185 & 0.249 \\
\hline & $A G$ & 262 & 306 & & 86 & 127 & \\
\hline & GG & 55 & 59 & & 12 & 30 & \\
\hline \multirow[t]{3}{*}{ rs12127377 } & $\mathrm{AA}$ & 349 & 521 & 0.017 & 139 & 197 & 0.230 \\
\hline & $A G$ & 243 & 282 & & 78 & 121 & \\
\hline & GG & 49 & 48 & & 10 & 24 & \\
\hline \multirow[t]{3}{*}{ rs11485101 } & AA & 564 & 738 & 0.656 & 206 & 305 & 0.430 \\
\hline & $A G$ & 72 & 112 & & 21 & 35 & \\
\hline & $\mathrm{GG}$ & 5 & 2 & & 0 & 2 & \\
\hline
\end{tabular}


Table 3 PCA-BCIT, PCA-LRT and permutation test on real data

\begin{tabular}{|c|c|c|c|c|c|}
\hline \multirow[t]{2}{*}{ Study } & \multirow[t]{2}{*}{ Strategy $\dagger$} & \multirow[t]{2}{*}{$99 \% \mathrm{Cl}$} & \multirow[t]{2}{*}{$95 \% \mathrm{Cl}$} & \multicolumn{2}{|c|}{$P$-value $\neq$} \\
\hline & & & & $P C A-L R T$ & Permutation test \\
\hline \multirow[t]{2}{*}{ PTPN22 } & 2 & $\begin{array}{c}(-5.4 \mathrm{E}-01,-4.7 \mathrm{E}-03)^{* *} \\
(-7.5 \mathrm{E}-16,6.9 \mathrm{E}-16)\end{array}$ & $\begin{array}{c}(-4.8 \mathrm{E}-01,-8.6 \mathrm{E}-02)^{*} \\
(-4.6 \mathrm{E}-16,4.2 \mathrm{E}-16)\end{array}$ & $0.006^{* *}$ & $0.002^{* *}$ \\
\hline & 3 & $\begin{array}{c}(1.7 \mathrm{E}-02,3.3 \mathrm{E}-01)^{* *} \\
(-2.5 \mathrm{E}-01,-1.3 \mathrm{E}-02)\end{array}$ & $\begin{array}{l}(4.9 \mathrm{E}-02,3.0 \mathrm{E}-01)^{*} \\
(-2.2 \mathrm{E}-01,-3.7 \mathrm{E}-02)\end{array}$ & $0.007^{* *}$ & $0.002^{* *}$ \\
\hline \multirow[t]{2}{*}{ OPRM1 } & 2 & $\begin{array}{c}(-1.2 \mathrm{E}+00,-1.1 \mathrm{E}-02)^{* *} \\
(-4.7 \mathrm{E}-16,5 \cdot 0 \mathrm{E}-16)\end{array}$ & $\begin{array}{c}(-1.1 \mathrm{E}+00,-1.8 \mathrm{E}-01)^{*} \\
(-3.7 \mathrm{E}-16,3.4 \mathrm{E}-16)\end{array}$ & 0.107 & $0.002^{* *}$ \\
\hline & 3 & $\begin{array}{c}(5.3 \mathrm{E}-02,1.4 \mathrm{E}+00)^{* *} \\
(-4.9 \mathrm{E}-01,-1.7 \mathrm{E}-02)\end{array}$ & $\begin{array}{l}(2.4 \mathrm{E}-01,1.2 \mathrm{E}+00)^{*} \\
(-4.2 \mathrm{E}-01,-8.0 \mathrm{E}-02)\end{array}$ & $0.012^{*}$ & $0.004^{* *}$ \\
\hline
\end{tabular}

†2 control-only extracting strategy (COES), 3 case-control extracting strategy (CES)

\# $^{*}$ significant at levels $\alpha=0.05\left(^{*}\right)$ and $\alpha=0.01\left(^{* *}\right)$.

based approaches. First of all, they are at least as powerful as genotype- and haplotype-based methods[7,16,17]. Secondly, they are able to capture LD information between correlated SNPs and easy to compute with needless consideration of multicollinearity and multiple testing. Thirdly, BCIT integrates point estimation and hypothesis testing as a single inferential statement of great intuitive appeal[29] and does not rely on the distributional assumption of the statistic used to calculate confidence interval[19,26-29].

While there have been several different but closely related forms of bootstrap confidence interval calculations[28], we focus on percentiles of the asymptotic distribution of $P C$ s for given confidence levels to estimate the confidence interval. $P C A-B C I T$ is a datalearning method[29], and shown to be valid and powerful for sufficiently large number of replicates in our study. Our investigation involving three strategies of extracting $P C$ s reveals that strategy 1 is invalid, while strategies 2 and 3 are acceptable. From analyses of real data we find that $P C A-B C I T$ is more favourable compared with $P C A-L R T$ and permutation test. It is suggested that a practical advantage of $P C A-B C I T$ is that it offers an intuitive measure of difference between cases and controls by using the set of SNPs $(P C$ scores) in a candidate region (Figure 3$)$. As extraction of $P C$ s through $C O E S$ is more in line with the principle of a case-control study, it will be our method of choice given that it has a comparable performance with $C E S$. Nevertheless, $P C A-B C I T$ has the limitation that it does not directly handle covariates as is usually done in a regression model.

\section{Conclusions}

$P C A-B C I T$ is both a valid and a powerful $P C A$-based method which captures multi-SNP information in study of gene-disease association. While extracting $P C$ s based on CAES, COES and CES all have good performances, it appears that $C O E S$ is more appropriate to use.

\section{Abbreviations}

SNP: single nucleotide polymorphism; HWE: Hardy-Weinberg Equilibrium; LD: linkage disequilibrium; LRT: logistic regression test; PCA: principle component analysis; PC: principle component; ES: extracting strategy; SES: separate case and control extracting strategy (strategy 0); CAES: case-based extracting strategy (strategy 1); COES: control-based extracting strategy (strategy 2); CES: combined case and control extracting strategy (strategy 3); BCIT: bootstrap confidence interval test.

\section{Acknowledgements}

This work was supported by grant from the National Natural Science Foundation of China (30871392). We wish to thank Dr. Dandan Zhang (Fudan University) and NARAC for supplying us with the data, and comments from the Associate Editor and anonymous referees which greatly improved the manuscript. Special thanks to referee for the insightful comment that extraction of PCS with controls is line with the case-control principles.

Table 4 Sample characteristics of heroin-induced positive responses on first use

\begin{tabular}{lccc}
\hline & Cases $(\boldsymbol{N}=\mathbf{9 1})$ & Controls $(\boldsymbol{N}=\mathbf{2 4 5})$ & $\boldsymbol{P}$-value \\
\hline Age (yrs) & $30.42 \pm 7.65$ & $30.93 \pm 8.18$ & 0.6057 \\
Women (\%) & 26.4 & 29.8 & 0.5384 \\
Age at onset (yrs) & $26.29 \pm 7.41$ & $26.97 \pm 7.89$ & 0.4760 \\
Reason for first use of heroin & & & 0.7173 \\
Curiousness & 79.1 & 75.1 & 4.9 \\
Peer pressure & 6.6 & 10.2 & \\
Physical disease & 7.7 & 6.1 & \\
Trouble & 5.5 & 3.8 & \\
Other reasons & 1.1 & & \\
\hline
\end{tabular}


Table 5 Armitage trend tests on nine OPRM1 SNPs and heroin-induced positive responses on first use

\begin{tabular}{|c|c|c|c|c|c|c|c|}
\hline \multirow{3}{*}{$\begin{array}{c}\text { SNP } \\
\text { rs1799971 }\end{array}$} & \multirow{3}{*}{$\begin{array}{c}\text { Genotype } \\
\text { AA }\end{array}$} & \multicolumn{4}{|c|}{ Count and frequency } & \multicolumn{2}{|c|}{ Armitage trend test } \\
\hline & & \multicolumn{2}{|c|}{ Cases } & \multicolumn{2}{|c|}{ Controls } & \multirow{2}{*}{$\begin{array}{c}\text { Chi-square } \\
0.003\end{array}$} & \multirow{2}{*}{$\begin{array}{c}P \text {-value } \\
0.9537\end{array}$} \\
\hline & & 55 & 0.604 & 150 & 0.622 & & \\
\hline & $A G$ & 27 & 0.297 & 64 & 0.266 & & \\
\hline & GG & 9 & 0.099 & 24 & 0.112 & & \\
\hline \multirow[t]{3}{*}{ rs510769 } & $\pi$ & 56 & 0.667 & 167 & 0.749 & 2.744 & 0.0976 \\
\hline & $\mathrm{TC}$ & 24 & 0.286 & 53 & 0.237 & & \\
\hline & CC & 4 & 0.048 & 4 & 0.018 & & \\
\hline \multirow[t]{3}{*}{ rs696522 } & AA & 64 & 0.762 & 215 & 0.907 & 11.097 & $0.0009^{*}$ \\
\hline & $A G$ & 19 & 0.226 & 21 & 0.089 & & \\
\hline & GG & 1 & 0.012 & 1 & 0.004 & & \\
\hline \multirow[t]{3}{*}{ rs1381376 } & $C C$ & 70 & 0.769 & 221 & 0.913 & 13.409 & $0.0003^{*}$ \\
\hline & $\mathrm{CT}$ & 20 & 0.220 & 21 & 0.087 & & \\
\hline & $\pi$ & 1 & 0.011 & 0 & 0.000 & & \\
\hline \multirow[t]{3}{*}{ rs3778151 } & GG & 66 & 0.733 & 215 & 0.896 & 14.655 & $0.0001^{*}$ \\
\hline & GA & 23 & 0.256 & 25 & 0.104 & & \\
\hline & AA & 1 & 0.011 & 0 & 0.000 & & \\
\hline \multirow[t]{3}{*}{ rs2075572 } & GG & 50 & 0.556 & 149 & 0.642 & 1.574 & 0.2096 \\
\hline & GC & 33 & 0.367 & 82 & 0.353 & & \\
\hline & $\mathrm{CC}$ & 7 & 0.078 & 11 & 0.047 & & \\
\hline \multirow[t]{3}{*}{ rs533586 } & $\pi$ & 68 & 0.840 & 203 & 0.868 & 0.761 & 0.3830 \\
\hline & $\mathrm{TC}$ & 12 & 0.148 & 31 & 0.132 & & \\
\hline & $C C$ & 1 & 0.012 & 0 & 0.000 & & \\
\hline \multirow[t]{3}{*}{ rs550014 } & $\pi$ & 78 & 0.857 & 203 & 0.832 & 0.093 & 0.7602 \\
\hline & $\mathrm{TC}$ & 12 & 0.132 & 41 & 0.168 & & \\
\hline & CC & 1 & 0.011 & 0 & 0.000 & & \\
\hline \multirow[t]{3}{*}{ rs658156 } & GG & 65 & 0.714 & 192 & 0.787 & 2.041 & 0.1531 \\
\hline & GA & 24 & 0.264 & 52 & 0.213 & & \\
\hline & AA & 1 & 0.011 & 0 & 0.000 & & \\
\hline
\end{tabular}

* significant after Bonferroni Correction.

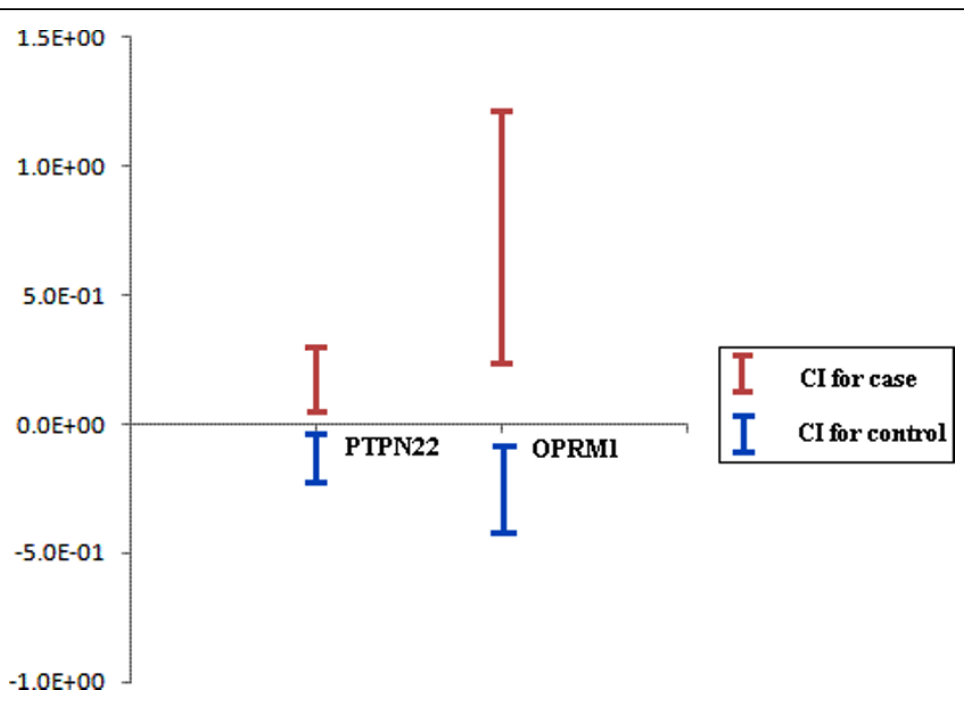

Figure 3 Real data analyses by PCA-BCIT with strategy 3 and confidence level 0.95 . The horizontal axis denotes studies and vertical axis mean(PC1), the statistic used to calculate confidence intervals for cases and controls. PCA-BCITs with strategy 3 were significant at confidence level 0.95 . 


\section{Author details}

'Department of Epidemiology and Health Statistics, School of Public Health, Shandong University, Jinan 250012, PR China. ${ }^{2}$ MRC Epidemiology Unit, Institute of Metabolic Science, Addenbrooke's Hospital, Cambridge CB2 OQQ, UK.

\section{Authors' contributions}

$\mathrm{QQP}, J \mathrm{HZ}$, and FZX conceptualized the study, acquired and analyzed the data and prepared for the manuscript. All authors approved the final manuscript.

Received: 6 December 2008

Accepted: 26 January 2010 Published: 26 January 2010

\section{References}

1. Morton NE, Collins A: Tests and estimates of allelic association in comples. Proc Natl Acad Sci USA 1998, 95:11389-11393.

2. Sasieni PD: From genotypes to genes: doubling the sample size. Biometrics 1997, 53:1253-1261.

3. Gordon D, Haynes C, Yang Y, Kramer PL, Finch SJ: Linear trend tests for case-control genetic association that incorporate random phenotype and genotype misclassification error. Genet Epidemiol 2007, 31:853-870.

4. Slager SL, Schaid DJ: Case-control studies of genetic markers: Power and sample size approximations for Armitage's test for trend. Human Heredity 2001, 52:149-153.

5. Sidak Z: On Multivariate Normal Probabilities of Rectangles: Their Dependence on Correlations. The Annals of Mathematical Statistics 1968, 39:1425-1434.

6. Sidak Z: On Probabilities of Rectangles in Multivariate Student Distributions: Their Dependence on Correlations. The Annals of Mathematical Statistics 1971, 42:169-175.

7. Zhang FY, Wagener D: An approach to incorporate linkage disequilibrium structure into genomic association analysis. Journal of Genetics and Genomics 2008, 35:381-385

8. Balding DJ: A tutorial on statistical methods for population association studies. Nature Reviews Genetics 2006, 7:781-791.

9. Schaid DJ, McDonnell SK, Hebbring SJ, Cunningham JM, Thibodeau SN: Nonparametric tests of association of multiple genes with human disease. American Journal of Human Genetics 2005, 76:780-793.

10. Becker T, Schumacher J, Cichon S, Baur MP, Knapp M: Haplotype interaction analysis of unlinked regions. Genetic Epidemiology 2005, 29:313-322.

11. Chapman JM, Cooper JD, Todd JA, Clayton DG: Detecting disease associations due to linkage disequilibrium using haplotype tags: A class of tests and the determinants of statistical power. Human Heredity 2003, 56:18-31.

12. Epstein MP, Satten GA: Inference on haplotype effects in case-control studies using unphased genotype data. American Journal of Human Genetics 2003, 73:1316-1329.

13. Fallin D, Cohen A, Essioux L, Chumakov I, Blumenfeld M, Cohen D, Schork NJ: Genetic analysis of case/control data using estimated haplotype frequencies: Application to APOE locus variation and Alzheimer's disease. Genome Research 2001, 11:143-151.

14. Stram DO, Pearce CL, Bretsky P, Freedman M, Hirschhorn JN, Altshuler D, Kolonel LN, Henderson BE, Thomas DC: Modeling and E-M estimation of haplotype-specific relative risks from genotype data for a case-control study of unrelated individuals. Human Heredity 2003, 55:179-190.

15. Clayton D, Chapman J, Cooper J: Use of unphased multilocus genotype data in indirect association studies. Genetic Epidemiology 2004, 27:415-428.

16. Gauderman WJ, Murcray C, Gilliland F, Conti DV: Testing association between disease and multiple SNPs in a candidate gene. Genetic Epidemiology 2007, 31:383-395.

17. Oh S, Park T: Association tests based on the principal-component analysis. BMC Proc 2007, 1(Suppl 1):S130.

18. Wang T, Elston RC: Improved power by use of a weighted score test for linkage disequilibrium mapping. American Journal of Human Genetics 2007, 80:353-360.

19. Heller G, Venkatraman ES: Resampling procedures to compare two survival distributions in the presence of right-censored data. Biometrics 1996, 52:1204-1213.
20. Plenge RM, Seielstad M, Padyukov L, Lee AT, Remmers EF, Ding B, Liew A, Khalili $\mathrm{H}$, Chandrasekaran A, Davies LRL, et al: TRAF1-C5 as a risk locus for rheumatoid arthritis - A genomewide study. New England Journal of Medicine 2007, 357:1199-1209.

21. Begovich AB, Carlton VE, Honigberg LA, Schrodi SJ, Chokkalingam AP, Alexander HC, Ardlie KG, Huang Q, Smith AM, Spoerke JM, et al: A missense single-nucleotide polymorphism in a gene encoding a protein tyrosine phosphatase (PTPN22) is associated with rheumatoid arthritis. Am J Hum Genet 2004, 75:330-337.

22. Carlton VEH, Hu XL, Chokkalingam AP, Schrodi SJ, Brandon R, Alexander HC, Chang M, Catanese JJ, Leong DU, Ardlie KG, et al: PTPN22 genetic variation: Evidence for multiple variants associated with rheumatoid arthritis. American Journal of Human Genetics 2005, 77:567-581.

23. Kallberg H, Padyukov L, Plenge RM, Ronnelid J, Gregersen PK, Helm-van Mil van der AHM, Toes REM, Huizinga TW, Klareskog L, Alfredsson L, et al: Gene-gene and gene-environment interactions involving HLA-DRB1, PTPN22, and smoking in two subsets of rheumatoid arthritis. American Journal of Human Genetics 2007, 80:867-875.

24. Plenge RM, Padyukov L, Remmers EF, Purcell S, Lee AT, Karlson EW, Wolfe F, Kastner DL, Alfredsson L, Altshuler D, et al: Replication of putative candidate-gene associations with rheumatoid arthritis in $>4,000$ samples from North America and Sweden: Association of susceptibility with PTPN22, CTLA4, and PADI4. American Journal of Human Genetics 2005, 77:1044-1060.

25. Zhang D, Shao C, Shao M, Yan P, Wang Y, Liu Y, Liu W, Lin T, Xie Y, Zhao Y, et al: Effect of mu-opioid receptor gene polymorphisms on heroininduced subjective responses in a Chinese population. Biol Psychiatry 2007, 61:1244-1251.

26. Carpenter J: Test Inversion Bootstrap Confidence Intervals. Journal of the Royal Statistical Society Series B (Statistical Methodology) 1999, 61:159-172.

27. Davison AC, Hinkley DV, Young GA: Recent developments in bootstrap methodology. Statistical Science 2003, 18:141-157.

28. DiCiccio TJ, Efron B: Bootstrap confidence intervals. Statistical Science 1996, 11:189-212.

29. Efron B: Bootstrap Methods: Another Look at the Jackknife. The Annals of Statistics 1979, 7:1-26.

doi:10.1186/1471-2156-11-6

Cite this article as: Peng et al: PCA-based bootstrap confidence interval tests for gene-disease association involving multiple SNPs. BMC Genetics 2010 11:6.

\section{Submit your next manuscript to BioMed Central and take full advantage of:}

- Convenient online submission

- Thorough peer review

- No space constraints or color figure charges

- Immediate publication on acceptance

- Inclusion in PubMed, CAS, Scopus and Google Scholar

- Research which is freely available for redistribution
C Biomed Central 